\title{
Assessment of the feasibility of serological monitoring and on-farm information about health status for the future meat inspection of fattening pigs
}

\section{Elina, Felin}

2019-01-01

Elina , F , Outi , H , Mari , H , Jukola , E \& Maria , F-A 2019 , ' Assessment of the feasibility of serological monitoring and on-farm information about health status for the future meat inspection of fattening pigs ' , Preventive Veterinary Medicine , vol. 162 , pp. 76-82 . https://doi.org/10.1016/j.prevetm

http://hdl.handle.net/10138/306205

https://doi.org/10.1016/j.prevetmed.2018.11.009

cc_by_nc_nd

acceptedVersion

Downloaded from Helda, University of Helsinki institutional repository.

This is an electronic reprint of the original article.

This reprint may differ from the original in pagination and typographic detail.

Please cite the original version. 


\section{Accepted Manuscript}

Title: Assessment of the feasibility of serological monitoring and on-farm information about health status for the future meat inspection of fattening pigs

Authors: Felin Elina, Hälli Outi, Heinonen Mari, Jukola Elias, Fredriksson-Ahomaa Maria

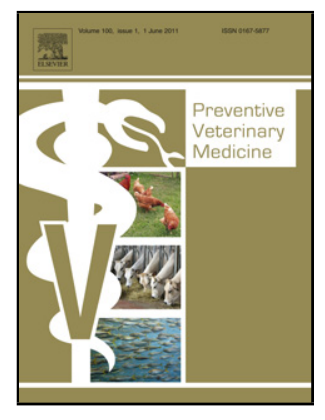

PII:

DOI:

Reference: $\quad$ PREVET 4589

S0167-5877(18)30315-5

To appear in: $\quad$ PREVET

Received date: $\quad 10$ May 2018

Revised date: $\quad 17$ November 2018

Accepted date: $\quad 18$ November 2018

Please cite this article as: Elina F, Outi H, Mari H, Jukola E, Maria F-Ahomaa, Assessment of the feasibility of serological monitoring and on-farm information about health status for the future meat inspection of fattening pigs, Preventive Veterinary Medicine (2018), https://doi.org/10.1016/j.prevetmed.2018.11.009

This is a PDF file of an unedited manuscript that has been accepted for publication. As a service to our customers we are providing this early version of the manuscript. The manuscript will undergo copyediting, typesetting, and review of the resulting proof before it is published in its final form. Please note that during the production process errors may be discovered which could affect the content, and all legal disclaimers that apply to the journal pertain. 
Assessment of the feasibility of serological monitoring and on-farm information about health status for the future meat inspection of fattening pigs

Felin Elina $^{\mathrm{a}^{*}}$, Hälli Outi ${ }^{\mathrm{b}}$, Heinonen Mari ${ }^{\mathrm{b}}$, Jukola Elias $^{\mathrm{a}}$ and Fredriksson-Ahomaa Maria ${ }^{\mathrm{a}}$

${ }^{a}$ Department of Food Hygiene and Environmental Health, Faculty of Veterinary Medicine, University of Helsinki, P.O Box 66, 00014 University of Helsinki, Finland; $\underline{\text { elina.felin@ helsinki.fi, elias.jukola@kolumbus.fi, maria.fredriksson-ahomaa@ helsinki.fi }}$

${ }^{\mathrm{b}}$ Department of Production Animal Medicine, Faculty of Veterinary Medicine, University of Helsinki, Paroninkuja 20, 04920 SAARENTAUS, Finland; outihalli75@gmail.com; mari.heinonen@helsinki.fi

*Correspondence. Tel: +358-50-4110216; E-mail: Elina.felin@helsinki.fi. 


\begin{abstract}
Current macroscopic meat inspection cannot detect the most common pork-borne pathogens
\end{abstract} (Salmonella spp., Yersinia enterocolitica and Toxoplasma gondii). Furthermore, food chain information (FCI) may not provide sufficient data for visual-only inspection, which is supposed to be the common way of inspection of pigs in the European Union. Our observational study aimed to evaluate the serological monitoring and the clinical evaluation of on-farm health status of pigs and assess the feasibility of these data as part of the FCI in meat inspection. We studied the serological status of Salmonella spp., Yersinia spp. and T. gondii in pigs during the fattening period. Additionally, we evaluated the association between on-farm health status and meat inspection findings. On 57 indoor fattening pig farms in Finland, we collected blood samples (mean of 20 pigs/farm) and assessed the on-farm health (coughing, tail biting, lameness) at the end of the fattening period. We visited 34 of these farms also at the beginning of the fattening for sampling and on-farm health evaluation of the same pigs. Meat inspection results were obtained after slaughter for all 57 farms. Salmonella seroprevalence was low at the end of the fattening period: it was $17.6 \%, 10.6 \%$ or $1.9 \%$, with the cut-off values of OD15\% (recommended by the test manufacturer), OD20\% (used by Danish monitoring programme) and OD40\% (used by German monitoring programme), respectively. The overall seroprevalence of Salmonella spp. and Yersinia spp. increased significantly $(\mathrm{P}<0.001)$ during the fattening period (from $8.1 \%$ to $17.2 \%$ and from $30.3 \%$ to $72.3 \%$, respectively), while the seroprevalence of $T$. gondii remained low $(<1 \%)$. The within-farm seroprevalences of Salmonella spp. and Yersinia spp. differed significantly between the farms and this farm-level serological data could be used as FCI for risk-based decisions to improve food safety. Such potentially feasible decisions could include additional carcass testing, carcass decontamination, carcass processing, slaughtering arrangements and improved biosecurity measures at the farm. However, risk mitigation targets and procedures must be carefully adjusted for each pathogen regarding also 
economic aspects. Tail biting observed on farm was associated with partial carcass condemnations and arthritis at slaughter. This information could be included in the FCI and used when making decisions regarding meat inspection procedure: visual-only or additional inspections.

\section{KEYWORDS}

Yersinia, Salmonella, Toxoplasma, pig, food chain information, meat inspection

\section{INTRODUCTION}

Meat inspection of pigs in EU consists of food chain information (FCI), ante-mortem inspection of live animals and post-mortem inspection of carcasses and offal (European Parliament and Council, 2004). Laboratory testing for Trichinella spp. is mandatory for all pigs, unless they are raised under officially recognised controlled housing conditions (European Commission, 2015). However, the most relevant food safety hazards in the context of pig meat in the EU (Salmonella spp., Yersinia enterocolitica, Toxoplasma gondii and Trichinella spp.) show no clinical symptoms nor gross pathological lesions in pigs and are not detectable within the current meat inspection, except Trichinella spp. by laboratory analysis (EFSA, 2011). Therefore, the meat inspection process should be modernised to control current food safety risks (EFSA, 2011).

A comprehensive pork carcass safety assurance system from 'the farm to the fork' is needed to ensure an effective control of the main hazards (EFSA, 2011). Control measures in the preharvest phase of production reduce the pathogens in fattening pigs and reduce the risk of transmitting them into the food chain. FCI should be the link between the farm and the slaughterhouse providing information related to food safety. However, available information 
on the prevalence of the above-mentioned food safety hazards at farms is limited. National Salmonella Control programmes exists in some EU countries, including Finland, but similar programmes for $Y$. enterocolitica and $T$. gondii are missing. EFSA (2011) concluded that improved FCI should be used to differentiate pig batches according to the food safety risks by sampling at farms or at slaughterhouses.

In addition to food safety issues, meat is also declared unfit for human consumption if it presents with patho-physiological changes or anomalies in consistency or in organoleptic quality (European Parliament and Council, 2004). These are mostly meat quality issues and do not pose a risk for food safety. The official EU post-mortem meat inspection of pigs shifted to visualonly meat inspection in 2014 (European Commission, 2014), although it is only partly implemented, among others due to requirements from third countries for exporting slaughterhouses (Alban et al., 2018). The change of legislation toward visual-only meat inspection was done to limit bacterial cross-contamination during meat inspection. Palpation and incision procedures should be carried out only for abnormal or suspect carcasses and offal. Healthy pigs are the prerequisite for visual-only meat inspection. Batches of pigs with high frequency of lesions should be slaughtered separately as they need a slower line speed and adequate human resources at trimming line or destined to the rework area. FCI should be a tool for food business operators and official veterinarians to recognize, prior to slaughter, the batches of pigs with high frequencies of lesions, which need additional inspection and are not suitable for visual-only meat inspection alone. In Finland, farmers currently report symptoms (e.g. tail biting, limping, coughing) occurring in the batch in FCI but it seems that this information is not always accurate (Felin et al., 2016). 
We hypothesize that serological profiles and on-farm health data could be used as FCI to mitigate food safety risks and predict condemnations, respectively. To test this hypothesis, we evaluated the seroprevalences of Salmonella spp., Yersinia spp. and T. gondii in pigs during the fattening period and assessed the feasibility of using serological results as part of the FCI in meat inspection. In addition, we examined associations between on-farm health data and condemnations at slaughter and the FCI in predicting condemnation rates. The associations between condemnations at slaughter and within-farm seroprevalences were analysed to confirm that these pathogens are not detectable in current meat inspection.

\section{MATERIAL AND METHODS}

\section{Data}

This was a follow-up study of fattening pigs in 57 indoor farms in Finland. Farms were allocated according to farm types: $39 \%$ were large fattening farms ( $\geq 1000$ pig places), $21 \%$ were small fattening farms (<1000 pig places) and $40 \%$ were farrow-to-finish farms. The study was performed during 2012-2014. The farms were selected through the willingness of the individual farmers to participate and according to the needs of another study investigating chronic pleurisy in fattening farms. The farms were located in southern Finland, and each slaughtered at least 1000 pigs per year. If the farm had several compartments, only one compartment per farm was included in our study.

A veterinarian visited the farms to take blood samples and to evaluate the health status of the pigs. All farms ( $\mathrm{n}=57)$ were visited at the end of the fattening period (Visit B, median 10 weeks, range 6-15 weeks after arrival). In addition to this, 34 farms were visited also at the beginning of the fattening period (Visit A, median 6 days, range 0-18 days after arrival). Pigs arrive to the fattening unit typically at the age of 9-10 weeks. 
The on-farm health status of the pigs in the compartment was evaluated by observing around 100 pigs per farm (Visit A: median 110 pigs, range 19-181; Visit B: median 105 pigs, range 19-180) for signs of lameness and fresh/healed tail biting. Coughing was evaluated by forcing all pigs in the compartment to stand up and then the number of coughing episodes during the following 5 minutes were registered. The coughing index was calculated by dividing the number of coughing episodes by the number of pigs in the compartment.

An average of 20 pigs (range 15-21) were randomly selected from various parts of the compartment and ear-tagged for blood sampling. Blood samples were collected from the jugular vein after catching the pigs with a snout snare. We stored the samples at $4{ }^{\circ} \mathrm{C}$ for up to 24 hours before centrifuging in the laboratory at $3000 \mathrm{rpm}$ for 10 minutes. Sera was separated and stored frozen in $-18{ }^{\circ} \mathrm{C}$ until analysis. In total, we sampled 653 individual pigs twice (at visits $\mathrm{A}$ and B) and in addition 487 pigs once (463 pigs only at visit B and 24 pigs only at visit A).

In total, we analysed 1793 blood samples using commercial enzyme-linked immunosorbent assay (ELISA) to test antibodies against Salmonella spp. (pigtype ${ }^{\circledR}$ Salmonella Ab, Qiagen, Leipzig, Germany), pathogenic Yersinia spp. (pigtype ${ }^{\circledR}$ Yersinia Ab, Qiagen, Leipzig, Germany) and T. gondii (pigtype ${ }^{\circledR}$ Toxoplasma Ab, Qiagen, Leipzig, Germany). The tests were performed and the results (S/P-ratio) were calculated and interpreted following the manufacturer's instructions. We considered samples with $\mathrm{S} / \mathrm{P}$ ratio $\geq 30 \%$ positive. OD $\%$ values for Salmonella spp. were calculated according to the following equation: OD $\%=\frac{\mathrm{S} / \mathrm{P} \times 100 \%}{2}$. We considered samples with an $\mathrm{OD} \geq 15 \%$ positive for Salmonella spp. Sensitivity and specificity of the used kits are nearly $100 \%$ according to the manufacturer. Pathogenic Yersinia spp. includes strains of $Y$. pestis, Y. pseudotuberculosis and $Y$. enterocolitica carrying the 
virulence plasmid. The serological reactions in Finnish fattening pigs are assumed to be mainly due to infection with $Y$. enterocolitica, although the presence of $Y$. pseudotuberculosis cannot be excluded (Felin et al., 2015).

The 57 farms in the study represented $4 \%$ of all the farms raising fattening pigs in Finland. For the sample size estimation, the seroprevalence of Yersinia spp. was assumed to be $57 \%, T$. gondii 3\% and Salmonella spp. 3\% at the end of the fattening (Felin et al., 2015). Consequently, the sample size (1116 fattening pigs at the end of the fattening and 653 fattening pigs sampled twice) was adequate to estimate seroprevalences of Salmonella spp. and T. gondii with 1-1.5\% precision and seroprevalence of Yersinia spp. with 3-4\% precision with 95\% confidence (Naing et al., 2006). Within each farm, the sample size of 20 fattening pigs enabled us to estimate the within-farm seroprevalence of Salmonella spp. and T. gondii with $95 \%$ confidence and $8 \%$ precision and Yersinia spp. with $95 \%$ confidence and $22 \%$ precision (Naing et al., 2006). The on-farm health status was estimated to be assessed with $95 \%$ confidence and $2-7 \%$ precision by evaluating 100 pigs/farm (Naing et al., 2006).

The feasibility of serological results as part of the FCI were evaluated by assessing differences in within-farm seroprevalences between farms and overall seroprevalences. Serological results were considered useful in targeting interventions when there were differences between farms and the overall seroprevalence was relevant or deductible.

We obtained meat inspection data from the slaughterhouse. Data covered all fattening pigs $(n=25552)$, originating from the 57 farms, that were slaughtered at the same time as the pigs studied in the same farms. 
The National Animal Experiment Board in Finland approved the experiments.

\section{Statistical analysis}

Pigs were considered 'seropositive' for a pathogen if the serum sample was positive. 'Withinfarm seroprevalence' means the number of positive samples from the farm per the number of samples taken from the farm, presented as a percentage.

\section{Variables in the logistic regression analyses for associations to the serological status of the} pigs

Statistical analyses were done to evaluate the comorbidity and the effect of the within-farm seroprevalence at the beginning of the fattening. The unit of interest was a pig. The dependent variables were 1) Yersinia seropositivity of the pig (seropositive/seronegative) at the beginning of fattening, 2) Yersinia seropositivity of the pig (seropositive/seronegative) at the end of fattening, 3) Salmonella seropositivity of the pig (seropositive/seronegative) at the beginning of fattening, 4) Salmonella seropositivity of the pig (seropositive/seronegative) at the end of fattening. Each dependent variable was separately analysed. Independent variables were a pig's simultaneous seropositivity to the other pathogen (Yersinia spp./Salmonella spp., binomial variable) than the dependent variable, and the within-farm seroprevalence (\%) of the studied pathogen at the beginning of fattening (scale variable) for dependents 2 and 4. Associations with $T$. gondii seropositivity were not analysed because of the low number of seropositive pigs.

\section{Variables in the logistic regression analyses for risk factors for condemnations at slaughter}

The associations between condemnations at slaughter and on-farm health data were analysed to examine if on-farm health data predicted condemnations. The unit of interest was a farm. The 
dependent variables were 1) Partial carcass condemnation rate, 2) Arthritis rate and 3) Abscess rate at the farm. Each dependent variable was separately analysed and introduced to the model as 'events/trials', e.g. 'n of condemned pigs/n of pigs'. Independent variables were scale farmlevel variables, which are shown in Table 1 (On-farm health of pigs). Independent variables also included the within-farm seroprevalences of Salmonella spp. and Yersinia spp. at the beginning and end of fattening. Each dependent variable was analysed twice: first with the factors at the beginning of fattening ( $\mathrm{n}=34$ farms) and then with the factors at the end of fattening ( $\mathrm{n}=57$ farms).

\section{Logistic regression analysis}

The association between each independent and dependent variable was first screened using a univariable generalized linear mixed model with farm as a random effect using the logistic link function. Independent variables with $\mathrm{P} \leq 0.1$ in the univariable analysis were introduced to the multivariable generalized linear mixed model with farm as a random effect using the logistic link function. Collinearity was checked by calculating Spearman correlations between independent variables in the final model. Correlations were at maximum moderate (all $<0.35$ ). Variables with $\mathrm{P}<0.05$ were considered statistically significant in the multivariable model.

\section{Other statistical analysis}

Wilcoxon signed-rank test was used to compare the within-farm seroprevalences at the beginning and at the end of the fattening. McNemar test was used to compare the seroprevalences of all pigs sampled twice at the beginning and the end of the fattening. The number of seropositive pigs originating from different farm types was compared using one-way analysis of variance (ANOVA) and Games Howell post hoc test. P-values <0.05 were considered to indicate statistical significance. 
Analyses were computed using the analytical software package SPSS® Statistics Version 23 (IBM Corp., New York, USA).

\section{RESULTS}

\section{Serological findings}

The apparent pig-level seroprevalences of Yersinia and Salmonella rose significantly $(\mathrm{P}<0.001)$ during the fattening period: Yersinia spp. from $30.3 \%$ to $72.3 \%$ and Salmonella spp. from $8.1 \%$ to $17.2 \%$ seropositive pigs, while the apparent seroprevalence of $T$. gondii remained at $0.6 \%$ (Table 2). The within-farm seroprevalences of Yersinia spp. and Salmonella spp. were significantly $(\mathrm{P}<0.01)$ higher at the end of the fattening than at the beginning. We observed significant differences between farms: within-farm seroprevalences ranged 0-100\% of Yersinia spp. and $0-55 \%$ of Salmonella spp. seropositive pigs at the end of fattening. T. gondii seropositive pigs were sporadic and within-farm seroprevalences ranged 0-10\%. On two farms, all tested pigs remained seronegative for all tested pathogens throughout the entire study.

At the end of the fattening, pigs at large fattening farms were more often Yersinia seropositive than pigs at farrow-to-finish farms $(70 \%$ vs. $62 \%$, respectively, $\mathrm{P}<0.05)$. No other differences between seroprevalences in pigs at different farm types were found.

The OD values of the Salmonella seropositive blood samples at the end of the fattening period were mostly between 15-30\% (Fig. 1). We used the cut-off value recommended by the manufacturer (OD15\%). The German Salmonella monitoring programme (QS Qualität und Sicherheit, 2018) use the cut-off value of OD40\% and Danish Salmonella control program OD20\% (Alban et al., 2012). Salmonella seroprevalence at the end of the fattening period was 
$17.6 \%, 10.6 \%$ or $1.9 \%$, with the cut-off values of OD15\%, OD20\% and OD40\%, respectively. Within-farm seroprevalences of Salmonella spp. ranged 0-20\% at the end of fattening with cutoff value OD $40 \%$.

\section{Associations between Salmonella and Yersinia seropositivity}

There were multiple associations between Salmonella and Yersinia seropositivity of individual pigs (Table 3). 'The within-farm Yersinia seroprevalence at the beginning of fattening' was a risk factor for Yersinia seropositivity in individual pigs at the end of the fattening (Table 3). Interestingly, the within-farm Salmonella seroprevalence at the beginning of fattening was not associated with individual pigs`seropositivity at the end of fattening $(\mathrm{P}=0.49)$.

\section{Risk factors for condemnations at slaughter}

In total, $7.1 \%(1818 / 25552)$ of the carcasses were subjected to partial condemnation, $4.8 \%$ (1221/25552) of the carcasses had abscesses and 3.3\% (833/25552) of the carcasses had arthritis lesions. Within-farm meat inspection results are shown in Table 1.

Significant risk factors for partial carcass condemnation rate at slaughter were the healed tailbiting rate at the end of the fattening period and the fresh tail-biting rate at the beginning of fattening (Table 4). No significant risk factors were observed for abscess rate, and only one for arthritis rate, namely the fresh tail-biting rate at the beginning of the fattening period (Table 4). The odds ratios detected were small, e.g. 1.009 for healed tail biting. This means that the odds of a pig carcass to be partially condemned were $0.9 \%$ higher when the percentage of pigs affected with healed tail biting in the farm increased by 1 per cent unit (Fig. 2). For example, if farm had a problem and healed tail biting rate was $50 \%$, the probability of pig carcass to be

partially condemned was $8.8 \%$ (OR $0.097 ; \mathrm{p}$ (probability)=OR/(1+OR); logit=b0+b1*x1; 
$\mathrm{OR}=\exp (\operatorname{logit}))$. Within-farm Salmonella and Yersinia seroprevalences did not associate with any of the meat inspection findings.

\section{DISCUSSION}

Yersinia and Salmonella seroprevalences increased significantly during the fattening period. Seropositive pigs at the beginning of fattening were likely to be infected before arriving at the fattening unit, because it takes at least 12 days for Yersinia and 7 days for Salmonella antibodies to rise after infection (Nielsen et al., 1995, 1996).

Yersinia seropositive pigs were detected more often at large fattening farms than at farrow-tofinish farms. This is in accordance with previous studies (Felin et al., 2015; Skjerve et al., 1998) and might result from the limited traffic of live animals to farrow-to-finish farms that seldom buy piglets from other farms. It has been shown that piglets may transport $Y$. enterocolitica to the fattening unit, where the bacteria spread effectively during fattening (Virtanen et al., 2012). This can also explain the results of our study: the high within-farm Yersinia seroprevalence at the beginning of fattening was associated with more seropositive pigs at the end. At seven (12\%) farms of which five (71\%) were farrow-to-finish farms, all tested pigs were Yersinia seronegative at the end of the fattening period. By serological monitoring at slaughter, farms with low Yersinia prevalence could be identified and these farms could be supported to maintain the low Yersinia prevalence e.g. through the possibility of buying piglets from Yersinianegative farms (Laukkanen-Ninios et al., 2014; Skjerve et al, 1998; Vilar et al., 2013; Virtanen et al., 2012). Currently, the prevalence of $Y$. enterocolitica is high in fattening pigs (especially in tonsils) at slaughter and therefore, good slaughter hygiene is as a major control measure to reduce carcass contamination. In addition, pigs from high-risk farms could be slaughtered at 
the end of the day and hot water decontamination of these carcasses could be used, though studies on pork carcasses are scarce (Laukkanen-Ninios et al., 2014).

Salmonella seroprevalence at the end of the fattening period was higher than expected considering the results from the Finnish Salmonella Control Program, where the prevalence of Salmonella culture-positive lymph node samples at slaughter has been $<0.1 \%$ and no Salmonella have been found in carcass swabs nor in pork during the 2010s (Anon., 2015; https://www.evira.fi/globalassets/elaimet/zoonoosikeskus/zoonoosit/taudit/salmonella/salmov alvontaohj_siat2016paivheinakuu2017.pdf, visited July 8, 2018). However, the OD values of our positive samples were relatively low. Low-dose infections during fattening with feed- or environment-associated Salmonella serotypes may explain this considerably high seroprevalence associated with the low OD values in positive pigs (Österberg and Wallgren, 2008; van Winsen et al., 2001). In addition, the specificity of the test in natural infections might be far less than $100 \%$ (Vico et al., 2010), especially when using low cut-off values, in which case the true prevalence decreases to a prevalence close to $0 \%$ (Reiczigel et al., 2010). Recent studies by Casanova-Higes et al. (2017) and Mainar-Jaime et al. (2018) found a significant relationship between on-farm Salmonella serology and Salmonella shedding at slaughter. However, if we wish to assess the risk of shedding at slaughter, reflecting the food safety aspect, the cut-off OD40\% would be more suitable (Casanova-Higes et al, 2017; Mainar-Jaime et al., 2017). In our study, $1.9 \%$ of the pigs were seropositive using a cut-off of OD40\%. The estimated true seroprevalence does not differ a lot from this apparent seroprevalence, because the test is expected to be highly specific but less sensitive with cut-off OD40\%.

In Denmark, meat-juice samples taken from fattening pigs at the time of slaughter has been proven to be an effective way of identifying high-risk herds for Salmonella as part of a reduction 
strategy (Alban et al., 2012). In contrast, the current Finnish Salmonella control programme operates as an eradication strategy (Finnish Food Safety Authority, 2018). Because the cost of Salmonella eradication on pig farms is very high, the eradication decision cannot be based only on highly sensitive serological monitoring. However, we found differences between farms and by serological testing we could monitor the Salmonella risk at farm level and react promptly by improving preventive measures at the farm. Limits of within-farm seroprevalence could be set to indicate an elevated food safety risk, which would result in bacteriological sampling at a farm and, in Finnish context, subsequent actions to eradicate the pathogen from the farm whenever Salmonella spp. is isolated. Limits and procedures, whenever considered as economically feasible, must be carefully adjusted in relation to mitigation targets in each country. For example, the largest slaughterhouse company in Denmark is using hot water decontamination for carcasses from high-risk farms (Alban et al., 2012).

We observed a clear positive association between an individual pig`s seropositivity for Salmonella spp. and Yersinia spp. Our result corresponds with our previous study in Finland (Felin et al., 2015), but is in contrast with findings from other countries (Nathues et al., 2013; Powell et al., 2016; Von Altrock et al., 2011). The difference between the results in Finland and other countries can be due to the low prevalence of Salmonella spp. infections in pigs in Finland affecting the epidemiology. However, none of the other studies analysed the association of seropositivity at pig level. The antigens used in the tests are specific, and no cross-reactivity is suspected between Yersinia and Salmonella (Nielsen et al., 1995).

The seroprevalence of $T$. gondii in the present study (0.7\%) was lower than in our previous study (3.2\%) (Felin et al., 2015). Considering the specificity of the test is not $100 \%$, the estimated true prevalence in present study was probably close to 0\% (Reiczigel et al., 2010). 
Difference in results may be due to the different ELISA test kits we utilized and partly due to farm selection. The test we used in present study is more specific than the test we used before (Felin et al., 2015, 2017). In present study, we only included farms that slaughter at least 1000 pigs per year, while most of the $T$. gondii seropositive pigs in our previous study arrived from small fattening farms (Felin et al., 2015). Pigs from smaller herds have been shown to have a higher risk for $T$. gondii seropositivity also in other studies (Limon et al., 2017; Villari et al., 2009). Because the true prevalence was near $0 \%$, the continuous serological monitoring would not be of use in risk ranking of indoor fattening farms slaughtering at least 1000 pigs per year in Finland. Serological monitoring could be beneficial if targeted to small fattening farms or outdoor farms as it would enable us to detect farms where improvement in biosecurity measures are needed and carcasses from herds with high prevalence of $T$. gondii antibodies could be directed to freezing or heating.

Trichinella spp. was not included in this study, because we analysed it in our previous study where all the samples were clearly negative (Felin et al., 2015). Since 2004, over 25 million pigs have been tested with digestion method, and only one positive pig was detected in 2010 (Finnish Food Safety Authority Evira, https://www.evira.fi/elaimet/zoonoosikeskus/zoonoosit/loisten-aiheuttamattaudit/trikinelloosi/, accessed in 8 July, 2018). If the Trichinella testing is to be diminished, as the legislation (European Commission, 2015) enables, then the serology would be a feasible way to survey the situation and the effectivity of the controlled housing conditions (EFSA, 2011). However, at present the digestion testing continues because of trade concerns (Alban et al., 2018). 
Salmonella and Yersinia seroprevalences at the end of fattening were higher in this study than what we have detected earlier with meat juice samples at slaughter $(3.1 \%$ and $56.6 \%$, respectively, Felin et al., 2015), and this is likely due to the different matrix (Wallander et al., 2015). Blood samples seems to result in higher OD values than meat juice samples and this should be considered when planning control programs (Vico et al., 2011; Wallander et al., 2015). Results at the end of the fattening in our study are supposed to reflect the serological status at slaughter which is of importance to food safety. In routine monitoring, sampling at slaughter would be more feasible than on-farm sampling.

Our data corresponded well with the national meat inspection statistics where the partial carcass condemnation rate was $6.4 \%$, abscess rate $3.2 \%$ and arthritis rate $3.0 \%$ for all fattening pigs slaughtered in 2013. The main shortage of our study was that the on-farm health status was assessed only on approximately 100 pigs per batch and the meat inspections findings represented the whole batch.

The fresh tail-biting rate at the beginning and the healed tail-biting rate at the end of fattening observed by the veterinarian on farm predicted partial carcass condemnations at slaughter well. We have shown in an earlier study (Felin et al., 2016), where tail biting was reported by farmers, that not all farmers reported the condition precisely. However, the farmers who did, tail-biting was a feasible predictor for condemnations in the batch, in addition to previous meat inspection findings. Also, other studies have shown that tail-biting victims have an increased incidence of abscesses and arthritis at slaughter, which leads to carcass condemnations (Marques et al., 2012; Valros et al., 2004). These results together show that a correctly reported tail-biting rate in FCI could be used in addition to the information on previous meat inspection results in slaughterhouses to predict the condemnations of incoming batches. This is not a food safety 
issue, but important to visual-only meat inspection. We should be able to, preferably beforehand, recognize batches needing additional inspection e.g. at the rework area. Farmers must be properly advised to carefully report this information and need to be willing to perform this duty. The seroprevalences at the end of fattening were not associated with post mortem findings, which was expected and supports our previous results (Felin et al., 2016). This means that we need tools (e.g. serological monitoring) to control these public health hazards in pork.

\section{Conclusions}

As part of a comprehensive pork carcass safety assurance system, serological monitoring could be used to allocate pig farms into risk categories for which targeted control measures could be applied. Our results show that antibodies to Yersinia and Salmonella increase significantly during the fattening period indicating that best timing for the serological screening is in the end of the fattening period or at the slaughterhouse. Differences between farms were found in the within-farm Yersinia and Salmonella seroprevalence at the end of the fattening. Thus, serological results in FCI give the possibility for the slaughterhouse to risk-rank farms according to the risk of shedding Yersinia spp., and slaughter the pigs from high-risk farms at the end of the day and use hot water decontamination for these carcasses. Serological monitoring of Salmonella would recognize the farms at risk and encourage to improve preventive measures at these farms. In Finland and other countries where the prevalence of Salmonella in fattening pigs is low, limits of within-farm seroprevalence could be set to indicate an elevated food safety risk, which would result in bacteriological sampling at the farm and subsequent procedures based upon the microbiological results. In countries like Finland where the seroprevalence of Toxoplasma is very low, no extensive serological monitoring for Toxoplasma at slaughterhouse is needed but monitoring could be beneficial if targeted to small fattening farms and outdoor farms. On-farm health status indicators (such as tail biting) together 
with previous meat inspection results could be used as part of the FCI to make decisions regarding meat inspection procedure: visual-only or additional inspections.

\section{DECLARATION OF INTEREST STATEMENT}

The authors declare no potential conflict of interest with respect to the research, authorship and publication of this article.

\section{ACKNOWLEDGEMENTS}

We thank Tapio Laurila, Minna Haimi-Hakala, Petronella Jansson and Claudio Oliviero for their contribution to data collection, Aki Pihlapuro for his expert assistance in statistical analysis and Maria Stark for excellent technical assistant. This study was supported by the Finnish Foundation of Veterinary Research and The Finnish Cultural Foundation and Ministry of Agriculture and Forestry of Finland.

\section{REFERENCES}

Alban, L., Baptista, F.M., Mogelmose, V., Sorensen, L.L., Christensen, H., Aabo, S., Dahl, J., 2012. Salmonella surveillance and control for finisher pigs and pork in Denmark - A case study. Food Res. Int., 45, 656-665.

Alban, L., Ruttscheidt Albuquerque, E., Cordeiro de Sá C.V.G., Buholzer, P., Vieira-Pinto, M., Langkabel, N., Meemken, D., Pointon, A., Hamilton, D., Abley, M., 2018. Modernisation of meat inspection of pigs - The world is on the move towards a more evidence-based type of inspection. Fleischwirtschaft International, 2, 8-15. 
Anonymous, 2015. Finland's report on trends and sources of zoonoses and zoonotic Agents in $\begin{array}{llll}\text { humans, } & \text { foodstuffs, } & \text { animals, } & \text { and }\end{array}$ https://www.evira.fi/globalassets/elaimet/zoonoosikeskus/zoonoosit/zoocountryreport14f i.pdf (accessed on 2018/1/27)

Casanova-Higes, A., Andrés-Barranco, S., Mainar-Jaime, R. C., 2017. Influence of on-farm pig Salmonella status on Salmonella shedding at slaughter. Zoonoses Public Health, 64, 328 336.

EFSA, 2011. Scientific opinion on the public health hazards to be covered by inspection of meat (swine). EFSA J., 9, 2351.

European Commission, 2014. Commission regulation (EU) No. 219/2014 of 7 March 2014 amending Annex I to Regulation (EC) No. 854/2004 of the European Parliament and of the Council as regards the specific requirements for post-mortem inspection of domestic swine.

European Commission, 2015. Commission implementing regulation (EU) 2015/1375 of 10 August 2015 laying down specific rules on official controls for Trichinella in meat.

European Parliament and Council, 2004. Regulation (EC) No. 854/2004 of the European Parliament and of the Council of 29 April 2004 laying down specific rules for the organisation of official controls on products of animal origin intended for human consumption.

Felin, E., Jukola, E., Raulo, S., Fredriksson-Ahomaa, M., 2015. Meat juice serology and improved food chain information as control tools for pork-related public health hazards. Zoonoses Public Health, 62, 456-464. 
Felin, E., Jukola, E., Raulo, S., Heinonen, J., Fredriksson-Ahomaa, M., 2016. Current food chain information provides insufficient information for modern meat inspection of pigs. Prev. Vet. Med., 127, 113-120.

Felin, E., Näreaho, A., Fredriksson-Ahomaa, M., 2017. Comparison of commercial ELISA tests for the detection of Toxoplasma antibodies in the meat juice of naturally infected pigs. Vet. Parasitol., 238, 30-34.

Finnish Food Safety Authority Evira, 2018. Risk assessment and cost-benefit analysis of Salmonella in feed and animal production. Evira Research Reports 3, 18.

Laukkanen-Ninios, R., Fredriksson-Ahomaa, M., Korkeala, H., 2014. Enteropathogenic Yersinia in the Pork Production Chain: Challenges for Control. Compr. Rev. Food Sci. F., $13,1165-1191$.

Limon, G., Beauvais, W., Dadios, N., Villena, I., Cockle, C., Blaga, R., Guitian, J., 2017. Crosssectional study of Toxoplasma gondii infection in pig farms in England. Foodborne Pathog. Dis., 14, 269-281.

Mainar-Jaime, R.C., Casanova-Higes, A., Andrés-Barranco, S., Vico, J.P., 2018. Looking for new approaches for the use of serology in the context of control programmes against pig salmonellosis. Zoonoses Public Health, 65, e222-e228.

Marques, B., Bernardi, M., Coelho, C., Almeida, M., Morales, O., Mores, T., Borowski, S., Barcellos, D., 2012. Influence of tail biting on weight gain, lesions and condemnations of finishing pigs. Pesqui. Vet. Brasil., 32, 967-974.

Methner, U., Rammler, N., Fehlhaber, K., Rösler, U., 2011. Salmonella status of pigs at slaughter - Bacteriological and serological analysis. Int. J. Food Microbiol., 151, 15-20. 
Naing, L., Winn, T., Rusli, B., 2006. Practical issues in calculating the sample size for prevalence studies. Arch. Orofacial Sci. 1, 9-14.

Nathues, C., Gruning, P., Fruth, A., Verspohl, J., Blaha, T., Kreienbrock, L., Merle, R., 2013. Campylobacter spp., Yersinia enterocolitica, and Salmonella enterica and their simultaneous occurrence in German fattening pig herds and their environment. J. Food Protect., 76, 1704-1711.

Nielsen, B., Baggesen, D., Bager, F., Haugegaard, J., Lind, P., 1995. The serological response to Salmonella serovars Typhimurium and Infantis in experimentally infected pigs. The time course followed with an indirect anti-LPS ELISA and bacteriological examinations. Vet. Microbiol., 47, 205-218.

Nielsen, B., Heisel, C., Wingstrand, A., 1996. Time course of the serological response to Yersinia enterocolitica O:3 in experimentally infected pigs. Vet. Microbiol., 48, 293-303.

Österberg, J., Wallgren, P., 2008. Effects of a challenge dose of Salmonella Typhimurium or Salmonella Yoruba on the patterns of excretion and antibody responses of pigs. Vet. Rec., $162,580-585$.

Powell, L.F., Cheney, T. E. A., Williamson, S., Guy, E., Smith, R. P., Davies, R. H., 2016. A prevalence study of Salmonella spp., Yersinia spp., Toxoplasma gondii and porcine reproductive and respiratory syndrome virus in UK pigs at slaughter. Epidemiol. Infect., $144,1538-1549$.

QS Qualität und Sicherheit GmbH, 2018. Guideline Salmonella Monitoring - Pigs, 1-16.

Reiczigel, J., Földi, J., Òzsvári, L., 2010. Exact confidence limits for prevalence of a disease with an imperfect diagnostic test. Epidemiol. Infect. 138, 1674-1678. 
Skjerve, E., Lium, B., Nielsen, B., Nesbakken, T., 1998. Control of Yersinia enterocolitica in pigs at herd level. Int. J. Food Microbiol. 45, 195-203.

Valros, A., Ahlström, S., Rintala, H., Häkkinen, T., Saloniemi H., 2004. The presence of tail damage in slaughter pigs in Finland and associations to carcass condemnations. Acta Agr. Scand. A-An, 54, 213-219.

van Winsen, R.L., van Nes, A., Keuzenkamp, D., Urlings, H.A.P., Lipman, L.J.A., Biesterveld, S., Snijders, J.M.A., Verheijden, J.H.M., van Knapen, F., 2001. Monitoring of transmission of Salmonella enterica serovars in pigs using bacteriological and serological detection methods. Vet. Microbiol., 80, 267-274.

Vico, J. P., Engel, B., Buist, W. G., Mainar-Jaime, R. C., 2010. Evaluation of three commercial enzyme-linked immunosorbent assays for the detection of antibodies against Salmonella spp. in meat juice from finishing pigs in Spain. Zoonoses Public Health, 57, $107-114$.

Vico, J.P., Mainar-Jaime, R.C., 2011. The use of meat juice or blood serum for the diagnosis of Salmonella infection in pigs and its possible implications on Salmonella control programs. J. Vet. Diagn. Invest., 23, 528-531.

Vilar, M.J., Virtanen, S., Heinonen, M., Korkeala, H., 2013. Management practices associated with the carriage of Yersinia enterocolitica in pigs at farm level. Foodborne Pathog. Dis., $10,595-602$.

Villari S, Vesco G, Petersen E, Crispo A, Buffolano, W., 2009. Risk factors for toxoplasmosis in pigs bred in Sicily, southern Italy. Vet Parasitol., 161:1-8. 
Virtanen, S., Salonen, L., Laukkanen-Ninios R., Fredriksson-Ahomaa, M., Korkeala, H., 2012. Piglets are a source of pathogenic Yersinia enterocolitica on fattening-pig farms. Appl. Environ. Microbiol., 78, 3000-3003.

von Altrock, A., Roesler, U., Waldmann, K. H., 2011. Herd factors associated with the serological Yersinia prevalence in fattening pig herds. Foodborne Pathog. Dis., 8, 12491255.

Wallander, C., Frössling, J., Vågsholm, I., Burrells, A., Lunden, A., 2015. Meat juice is not a homogeneous serological matrix. Foodborne Pathog. Dis., 12, 280-288. 
Figure Caption

Fig. 1. Salmonella OD values $(\%)$ of 1116 blood samples taken from fattening pigs at the end of the fattening period in Finland

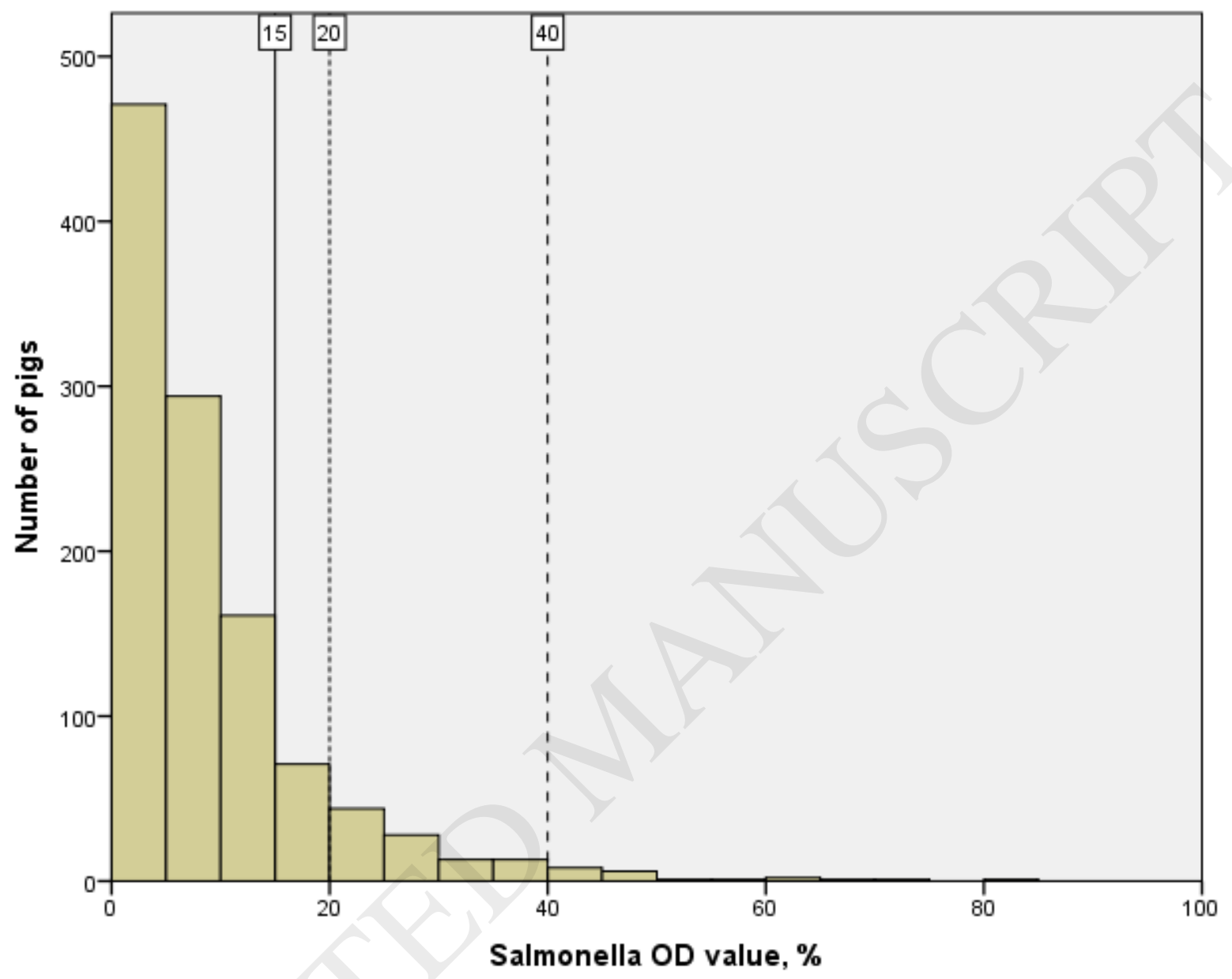

Fig. 2. The association between the healed tail biting injuries observed by veterinarian at the farm and partial carcass condemnation rate in meat inspection of fattening pigs from 57 farms in Finland. 


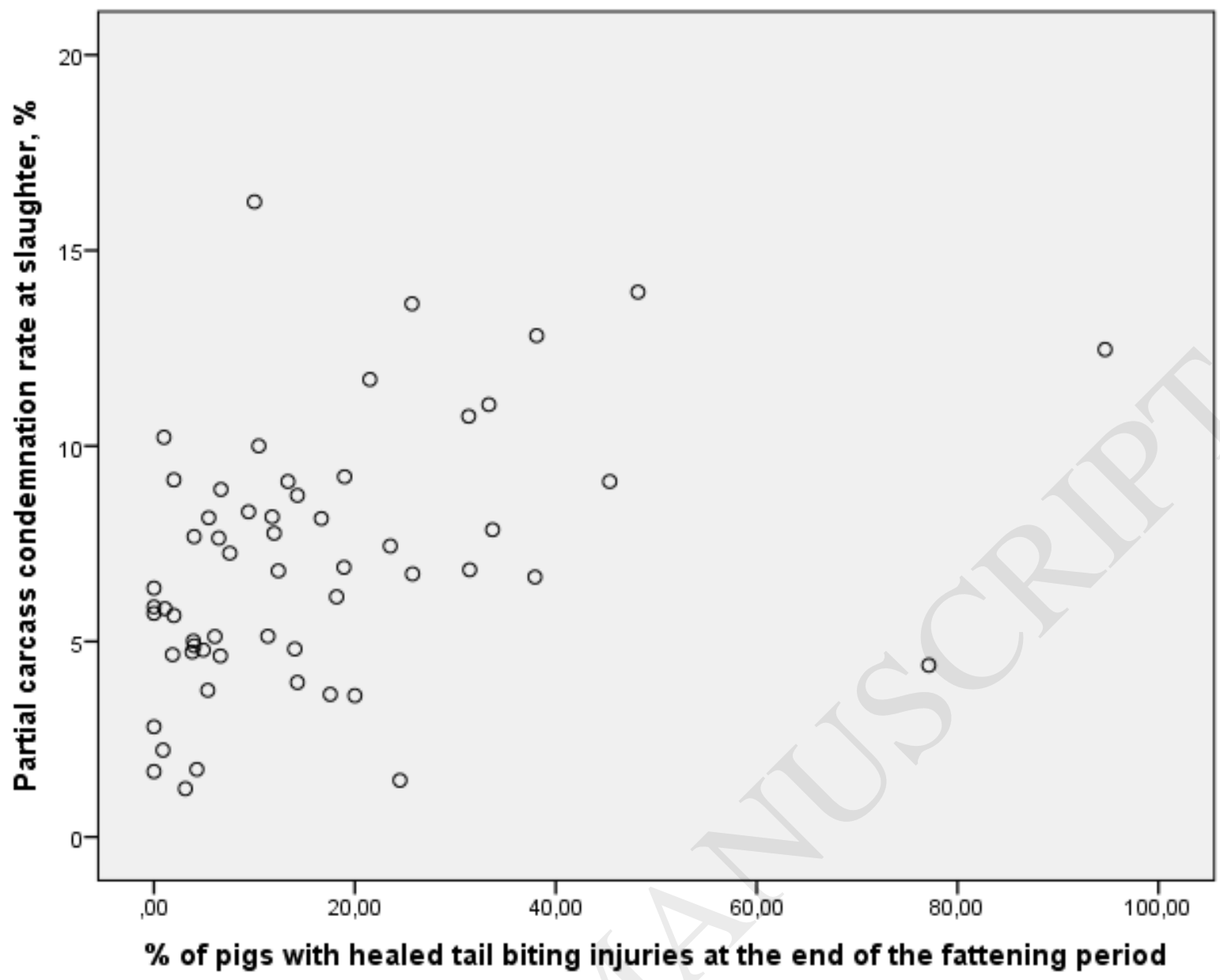


Table 1. Farm-level data considering on-farm health and meat inspection findings in fattening pigs from pig farms in Finland

\begin{tabular}{|c|c|c|c|c|c|}
\hline \multirow[t]{2}{*}{ Subject } & \multirow[t]{2}{*}{ Collected data } & \multirow{2}{*}{$\begin{array}{l}\text { No. of } \\
\text { farms }\end{array}$} & \multicolumn{3}{|c|}{ Description of data } \\
\hline & & & Mean & Median & Range \\
\hline \multirow[t]{8}{*}{$\begin{array}{l}\text { On-farm health } \\
\text { of pigs }\end{array}$} & $\begin{array}{l}\text { Coughing index at the beginning of } \\
\text { the fattening period }\end{array}$ & 34 & $0.6 \%$ & $0.5 \%$ & $0-2.6 \%$ \\
\hline & $\begin{array}{l}\text { Coughing index at the end of the } \\
\text { fattening period }^{\text {a }}\end{array}$ & 57 & $0.6 \%$ & $0 \%$ & $0-5.5 \%$ \\
\hline & $\begin{array}{l}\% \text { of pigs with fresh tail-biting } \\
\text { injuries at the beginning of the } \\
\text { fattening period }\end{array}$ & 34 & $2.8 \%$ & $0 \%$ & $0-36.1 \%$ \\
\hline & $\begin{array}{l}\% \text { of pigs with fresh tail-biting } \\
\text { injuries at the end of the fattening } \\
\text { period }\end{array}$ & 57 & $0.7 \%$ & $0 \%$ & $0-11.2 \%$ \\
\hline & $\begin{array}{l}\% \text { of pigs with healed tail-biting } \\
\text { injuries at the beginning of the } \\
\text { fattening period }\end{array}$ & 34 & $8.0 \%$ & $2.7 \%$ & $0-38.0 \%$ \\
\hline & $\begin{array}{l}\% \text { of pigs with healed tail-biting } \\
\text { injuries at the end of the fattening } \\
\text { period }\end{array}$ & 57 & $16.1 \%$ & $11.3 \%$ & $0-94.7 \%$ \\
\hline & $\begin{array}{l}\% \text { of lame pigs, at the beginning of the } \\
\text { fattening period }\end{array}$ & 34 & $0.9 \%$ & $0 \%$ & $0-6.0 \%$ \\
\hline & $\begin{array}{l}\% \text { of lame pigs, at the end of the } \\
\text { fattening period }\end{array}$ & 57 & $1.7 \%$ & $1.7 \%$ & $0-8.0 \%$ \\
\hline \multirow{3}{*}{$\begin{array}{l}\text { Within-farm } \\
\text { meat } \\
\text { inspection data } \\
\text { at slaughter }\end{array}$} & Partial carcass condemnation $\%$ & 57 & $7.0 \%$ & $6.8 \%$ & $1.0-16.0 \%$ \\
\hline & Arthritis \% & 57 & $3.3 \%$ & $3.1 \%$ & $0-10.0 \%$ \\
\hline & Abscess \% & 57 & $4.5 \%$ & $3.8 \%$ & $1.0-13.0 \%$ \\
\hline
\end{tabular}

${ }^{\text {a }}$ Coughing index: Pigs in one compartment were forced to stand up, the coughing episodes were recorded for 5 minutes and the number was divided with the number of pigs in the compartment. 
Table 2. Serological results of blood samples taken at the beginning (A) and at the end (B) of the fattening period from fattening pigs in Finland

\begin{tabular}{|c|c|c|c|c|c|c|c|c|c|c|c|}
\hline \multirow{3}{*}{ Bacteria } & \multicolumn{11}{|c|}{ Seropositive $^{\mathrm{a}}$} \\
\hline & \multirow{2}{*}{\multicolumn{2}{|c|}{$\begin{array}{l}(\mathrm{n}=1116) \\
\text { Sampling B }\end{array}$}} & \multirow{2}{*}{\multicolumn{2}{|c|}{$\begin{array}{l}(\mathrm{n}=57) \\
\text { Sampling B }\end{array}$}} & \multirow{2}{*}{\multicolumn{2}{|c|}{$\begin{array}{l}\text { Pigs } \quad(n=653 \\
\text { twice } \\
\text { Sampling A } \\
\end{array}$}} & \multicolumn{2}{|c|}{ sampled } & \multirow{2}{*}{\multicolumn{3}{|c|}{$\begin{array}{l}\begin{array}{l}\text { Farms } \quad(n=34) \\
\text { twice }\end{array} \\
\text { Sampling A }\end{array}$}} \\
\hline & & & & & & & Samp & ing B & & & \\
\hline $\begin{array}{l}\text { Salmonella } \\
\text { spp. }\end{array}$ & 196 & $17.6 \%$ & 52 & $91.2 \%$ & 53 & $8.1 \%$ & 112 & $17.2 \%$ & $23 \quad 67.6 \%$ & 30 & $88.2 \%$ \\
\hline $\begin{array}{l}\text { Pathogenic } \\
\text { Yersinia } \\
\text { spp. }\end{array}$ & 738 & $66.1 \%$ & 50 & $87.7 \%$ & 198 & $30.3 \%$ & 472 & $72.3 \%$ & $58.8 \%$ & 32 & $94.1 \%$ \\
\hline $\begin{array}{l}\text { Toxoplasma } \\
\text { gondii }\end{array}$ & 8 & $0.7 \%$ & 6 & $10.5 \%$ & 4 & $0.6 \%$ & 4 & $0.6 \%$ & $4 \quad 11.8 \%$ & & $8.8 \%$ \\
\hline
\end{tabular}


Table 3. Variables significantly $(\mathrm{P}<0.05)$ associated with Yersinia and Salmonella seropositivity in fattening pigs in Finland during 2012-2014 in final models using a generalized linear mixed model with farm as a random effect

\begin{tabular}{|c|c|c|c|c|c|c|}
\hline Dependent & Factor & $\begin{array}{l}\text { Odds } \\
\text { ratio }\end{array}$ & $\begin{array}{l}95 \% \\
\text { CI }\end{array}$ & $\begin{array}{l}\mathrm{P} \text { - } \\
\text { value }\end{array}$ & $\begin{array}{l}\text { No. of } \\
\text { pigs }\end{array}$ & $\begin{array}{l}\text { No. of } \\
\text { farms }\end{array}$ \\
\hline $\begin{array}{l}\text { Yersinia seropositivity of } \\
\text { the pig } \\
\text { (seropositive/seronegative) } \\
\text { at the beginning of } \\
\text { fattening }\end{array}$ & $\begin{array}{l}\text { Simultaneous } \\
\text { Salmonella } \\
\text { seropositivity of } \\
\text { the pig }\end{array}$ & 6.37 & $\begin{array}{l}2.59- \\
15.69\end{array}$ & $<0.001$ & 677 & 34 \\
\hline \multirow[t]{2}{*}{$\begin{array}{l}\text { Yersinia seropositivity of } \\
\text { the pig } \\
\text { (seropositive/seronegative) } \\
\text { at the end of fattening }\end{array}$} & $\begin{array}{l}\text { Simultaneous } \\
\text { Salmonella } \\
\text { seropositivity of } \\
\text { the pig }\end{array}$ & 6.47 & $\begin{array}{l}2.33- \\
17.94\end{array}$ & $<0.001$ & 656 & 34 \\
\hline & $\begin{array}{l}\text { The within-farm } \\
\text { Yersinia } \\
\text { seroprevalence } \\
\text { (\%) at the } \\
\text { beginning of } \\
\text { fattening }\end{array}$ & 1.03 & $\begin{array}{l}1.01- \\
1.05\end{array}$ & 0.005 & 656 & 34 \\
\hline $\begin{array}{l}\text { Salmonella seropositivity } \\
\text { of the pig } \\
\text { (seropositive/seronegative) } \\
\text { at the beginning of } \\
\text { fattening }\end{array}$ & $\begin{array}{l}\text { Simultaneous } \\
\text { Yersinia } \\
\text { seropositivity of } \\
\text { the pig }\end{array}$ & 5.10 & $\begin{array}{l}2.94- \\
8.85\end{array}$ & $<0.001$ & 677 & 34 \\
\hline $\begin{array}{l}\text { Salmonella seropositivity } \\
\text { of the pig } \\
\text { (seropositive/seronegative) } \\
\text { at the end of fattening }\end{array}$ & $\begin{array}{l}\text { Simultaneous } \\
\text { Yersinia } \\
\text { seropositivity of } \\
\text { the pig }\end{array}$ & 4.05 & $\begin{array}{l}2.44- \\
6.74\end{array}$ & $<0.001$ & 1116 & 57 \\
\hline
\end{tabular}


Table 4. Farm-level factors significantly $(\mathrm{P}<0.05)$ associated with farm-level condemnation rates in fattening pigs in Finland using a generalized linear mixed model with farm as a random effect

\begin{tabular}{llllll}
\hline Dependent & Factor & Odds ratio & $95 \% \mathrm{CI}$ & P-value & $\begin{array}{l}\text { No. of } \\
\text { farms }\end{array}$ \\
\hline $\begin{array}{l}\text { Partial } \\
\text { condemnation } \\
\text { rate }\end{array}$ & Fresh tail biting A & 1.028 & $1.000-1.057$ & 0.047 & 34 \\
& Healed tail biting B & 1.009 & $1.002-1.016$ & 0.008 & 57 \\
Arthritis rate & Fresh tail biting A & 1.035 & $1.010-1.061$ & 0.008 & 34 \\
\hline
\end{tabular}

${ }^{a} \mathrm{~A}=$ at the beginning of the fattening,

${ }^{\mathrm{b}} \mathrm{B}=$ at the end of the fattening 